\title{
Comparison between infiltration and inferior alveolar nerve block anesthesia in extraction of non-vital mandibular posterior teeth (prospective clinical study)
}

Accepted: 29/1/2014

\begin{tabular}{ccc}
\hline Rozh M .Hussein * & DilmanN.Muhammad * & Othman A. Omar * \\
\hline & Abstract
\end{tabular}

Background and objective: Infiltration anesthesia for the posterior region of the mandible has been routinely avoided because of its questionable effectiveness related to the dense cortical bone of the mandible. The aim of this study was to evaluate the effectiveness of infiltration anesthetic technique on mandibular posterior non-vital teeth.

Methods: Forty four patients aged between 13and 73 years who attended the Department of Oral and Maxillofacial Surgery in the College of Dentistry, Hawler Medical University for extraction of posterior non vital tooth were included in this study. For the infiltration anesthetic technique, patient's approval was taken. The patients were equally divided into two groups. Group (1) received $0.6 \mathrm{ml}$ out of $1.8 \mathrm{ml}$ of $2 \%$ lidocaine with $1: 80000$ adrenaline injection bucally and the same amount infiltration lingually opposite the intended tooth. Group (2) received $1.5 \mathrm{ml}$ out of $1.8 \mathrm{ml}$ of $2 \%$ lidocaine with $1: 80000$ and the remaining $0.3 \mathrm{ml}$ was injected for long buccal nerve anesthesia.

Results: In group (1), $68.2 \%$ had no pain during extraction, showed statistically highly significant difference $(P=009)$. Gender showed no significant difference. In group (2), 100 $\%$ of the patients had no pain during extraction.

Conclusion: Infiltration anesthesia for non-vital mandibular molars is effective as a substitute for inferior alveolar block technique.

Keywords: Infiltration technique, inferior alveolar nerve block, non-vital teeth, lidocaine.

\section{Introduction}

Pain control is an important part of dentistry. The inferior alveolar nerve block is the most frequently used injection technique for achieving local anesthesia for mandibular restorative and surgical procedures of the posterior region. Successful inferior alveolar nerve block involves a degree of difficulties that makes the injection stressful for both the clinician and the patient. ${ }^{1}$ Major postoperative complications may occur with the use of block anesthesia of the inferior alveolar nerve which includes: Prolonged mandibular anesthesia, during this time the patient may injure his or her tongue or lip in a variety of ways, systemic toxicity from iatrogenic intra- arterial injection of local anesthetic solution, injury to the inferior alveolar nerve, ${ }^{2}$ difficulty in achieving anesthesia because of anatomic variations, deep and invasive needle penetration; parasthesia; muscle trismus; hematoma formation; high incidence of positive aspiration; and difficulty in hemostasis in patients with bleeding disorders. ${ }^{3}$ Infiltration anesthesia has been avoided in the mandibular molar regions because of dens bone that does not allow adequate diffusion of the anesthetic solution to the bone. ${ }^{4}$ To the best of our knowledge, no previous study investigated the effectiveness of infiltration anesthesia in dental extraction of mandibular posterior teeth, most of the studies used infiltration anesthesia as an alternative to block anesthesia for mandibular posterior teeth in placing dental implants. This study focused on the effectiveness of mandibular infiltration compared with inferior alveolar nerve block in the extraction of non vital mandibular posterior teeth.

* Department of Oral and Maxillofacial Surgery, College of Dentistry, Hawler Medical University, Erbil, Iraq. 


\section{Methods}

The study type is prospective cohort clinical study. The study included 44 patients who attended the Department of Oral and Maxillofacial Surgery, College of Dentistry, Hawler Medical University for extraction of non vital lower posterior tooth/teeth. Consent was obtained from each patient participated in this study. The patients were equally divided into two groups. Group 1: Infiltration technique was used to anaesthetize mandibular posterior non vital symptomless teeth using $0.6 \mathrm{ml}$ out of $1.8 \mathrm{ml}$ of $2 \%$ lidocaine from one dental cartridge with 1:80000 adrenaline injections. Two injections $0.6 \mathrm{ml}$ for each tooth were given against and parallel to the long axes of the offended tooth. One injection was in the buccal vestibule targeting the long buccal nerve by which soft and hard tissues were anaesthetized, using short needle and dental syringe. The second injection was in the lingual vestibule of the floor of the mouth by which lingual soft and hard tissue was anaesthetized, using short needle and dental syringe. Group 2: two injections were given $1.5 \mathrm{ml}$ of $2 \%$ lidocaine used for inferior alveolar nerve block, and the second one was performed with the remaining $0.3 \mathrm{ml}$ for long buccal nerve infiltration. Teeth included in this study were non vital, non infected mandibular premolars, first and second molars. Local anesthesia and dental extraction was performed for all cases by the same surgeon. The success of anesthesia was checked with in 3-5 minute subjectively (verbal) by asking the patient about the presence of numbness in the anaesthetized region. Objective test was also done by applying a probe at depth of the gingival margin from mesial to distal buccally and lingually, while the reaction and response of the patient was noted. Visual analogue pain scale used during dental extraction to assess the pain. This scale labeled no pain, mild, moderate and severs pain. ${ }^{5}$ If there was no pain the extraction was completed using dental forceps or elevators, and then instructions were given to the patient. If pain was observed whether mild, moderate or severe in group (1) the procedure was ceased and inferior alveolar nerve blocked was given to the patient.

Statistical analysis: Exact fisher test was used for analysis of the data with significance level at $P \leq 0.05$.

\section{Results}

A total of 44 patients (21 female and 23 male) with a mean age of 39.2 year were enrolled in this study. Pain during extraction and the success rate of anesthesia between the two groups is shown in Table 1.

Table 1: Pain experienced during dental extraction in relation to the anesthetic technique.

\begin{tabular}{|c|c|c|c|c|c|}
\hline & & & \multicolumn{2}{|l|}{ Pain } & \multirow[t]{2}{*}{ Total } \\
\hline & & & No & Yes & \\
\hline \multirow[t]{2}{*}{ GROUP } & & $\begin{array}{l}\text { Count } \\
\% \text { within GROUP }\end{array}$ & $\begin{array}{l}15 \\
68.2 \%\end{array}$ & $\begin{array}{l}7 \\
31.8 \%\end{array}$ & $\begin{array}{l}22 \\
100.0 \%\end{array}$ \\
\hline & Group 2 & $\begin{array}{l}\text { Count } \\
\% \text { within GROUP }\end{array}$ & $\begin{array}{l}22 \\
100.0 \%\end{array}$ & $\begin{array}{l}0 \\
.0 \%\end{array}$ & $\begin{array}{l}22 \\
100.0 \%\end{array}$ \\
\hline \multirow[t]{2}{*}{ Total } & $\begin{array}{l}\text { Count } \\
\text { \% within G }\end{array}$ & ROUP & $\begin{array}{l}37 \\
84.1 \%\end{array}$ & $\begin{array}{l}7 \\
15.9 \%\end{array}$ & $\begin{array}{l}44 \\
100.0 \%\end{array}$ \\
\hline & $\mathrm{P}$ Value & & \multicolumn{3}{|c|}{ Probability point } \\
\hline $\begin{array}{l}\text { Fisher's Exact } \\
\text { Test }\end{array}$ & $\begin{array}{l}0.009 \\
0.009\end{array}$ & & \multicolumn{2}{|l|}{0.004} & \\
\hline
\end{tabular}


http://dx.doi.org/10.15218/zjms.2014.0040

Table 2: Pain experienced during dental extraction in relation to the gender.

\begin{tabular}{|c|c|c|c|c|c|}
\hline & & & Pain & & Total \\
\hline & & & No & Yes & \\
\hline Sex & female & $\begin{array}{l}\text { Count } \\
\% \text { within sex }\end{array}$ & $\begin{array}{l}16 \\
76.2 \%\end{array}$ & $\begin{array}{l}5 \\
23.8 \%\end{array}$ & $\begin{array}{l}21 \\
100.0 \%\end{array}$ \\
\hline Total & $\begin{array}{l}\text { Male } \\
\text { Count } \\
\% \text { withir }\end{array}$ & $\begin{array}{l}\text { Count } \\
\% \text { within sex }\end{array}$ & $\begin{array}{l}21 \\
100.0 \% \\
37 \\
84.1 \%\end{array}$ & $\begin{array}{l}2 \\
.0 \% \\
7 \\
15.9 \%\end{array}$ & $\begin{array}{l}23 \\
100.0 \% \\
44 \\
100.0 \%\end{array}$ \\
\hline & P Value & & Probabili & point & \\
\hline Fisher's Exact Test & $\begin{array}{l}0.232 \\
0.232\end{array}$ & & 0.134 & & \\
\hline
\end{tabular}

The success rate of anesthesia in group (1) was $68.2 \%$ and $100 \%$ in group (2). The difference was highly significant $(P=0.009)$. Gender showed no significant difference in the success of the technique as shown in Table 2.

\section{Discussion}

Inferior alveolar nerve is a branch from the posterior division of the mandibular nerve and enters the mandibular canal to supply the teeth of the lower jaw and emerges through the mental foramen (mental nerve) to supply the skin of the chin. Before entering the canal, it gives off the mylohyoid nerve which supplies the mylohyoid muscle and the anterior belly of the digastric muscle. Lingual nerve which is also a branch from the posterior division of the mandibular nerve descends in front of the inferior alveolar nerve and enters the mouth, it then runs forward on the side of the tongue and crosses the submandibular duct. In its course, it is joined by the chorda tympani nerve and it supplies the mucous membrane of the anterior two thirds of the tongue and the floor of the mouth. It also gives off preganglionic parasympathetic secretomotor fibers to the submandibular ganglion. Buccal nerve which branches from the anterior division of the mandibular nerve supplies the skin and the mucous membrane of the cheek. ${ }^{6}$ In this study, there was no any ocular complications found in the group of patients which receive inferior alveolar nerve block, while Choi et al reported 12 cases of diploia, in their systematic review. In the literature, it seems that ocular complications that occur immediately after IAN block, due to intraarterial injection of the local anesthetics. ${ }^{7}$ Therefore considering all the complications and side effects of IAN block, supraperiosteal infiltration technique is easier to practice, complication rate is lesser than IAN block, and its anesthetic effect is shorter and it is much more tolerable in terms of patient's pain sufferance and postoperative comfort. Mandibular bone is considered as too dense and too compact and because of this dense structure, it is thought that local anesthetic cannot be diffused into the medullary space of mandible by supraperiosteal infiltration. In the present study, 15 patients out of 44 were completely pain free by using infiltration for extracting non vital posterior teeth. These data strength the knowledge of existence of accessory foramina in the mandible, it has been found that 2449 accessory or unnamed foramina in 300 dried human mandibles. ${ }^{8}$ Madeira et al. $^{9}$ reported the presence of accessory foramina in the human mandibule in 87.3 to $96.2 \%$ of specimens studied. Pogrel et al reported that branches of the mental nerve reenter the labial 
http://dx.doi.org/10.15218/zjms.2014.0040

(lateral) surface of the mandible to supply lower incisors. Based on the above mentioned findings and our results, the success of supraperiosteal infiltration anesthesia at the posterior region of the mandible might be related with the possibility of diffusion of local anesthetic solution within the bony structures. ${ }^{10}$ Because the non-vital teeth lack pulpal tissue and since the IAN supply the dental pulp, so giving anesthesia to the IAN is no longer necessary and to avoid its complications its more practical and scientific to use infiltration technique to anaesthetized the long buccal nerve and lingual nerve. A reason that infiltration techniques may not be the first choice in the adult mandible is because practitioners tend to think that the thick cortical plate prevents diffusion of solution into the cancellous bone and, therefore, to the nerves supplying the pulps of the teeth. ${ }^{11}$ In the present study, 22 posterior teeth were extracted by using infiltration anesthetic technique, divided as eight premolars, two third molar and the rest were first and second molars. The pain recorded during checking the anesthesia was in five premolars and two third molars, while all the first and second molars were pain free. Thus, infiltration technique can be utilized safely as an alternative method of mandibular block anesthesia for extracting non vital posterior teeth particularly $1^{\text {st }}$ and $2^{\text {nd }}$ molars.

\section{Conclusion}

Buccal and lingual Infiltration technique provides an alternative approach to establish effective anesthesia for mandibular posterior teeth during intra-alveolar dental extraction procedures.

\section{Conflicts of interest}

The authors report no conflicts of interest.

\section{References}

1. Oulis CJ, Vadiakas GP, VasilopoulouA. The effectiveness of mandibular infiltration compared to mandibular block anesthesia in treating primary molars in children. Pediatr Dent J 1996; 18:301-5.
2. Heller AA, Shankland WE. Alternative to the inferior alveolar nerve block anesthesia when placing mandibular dental implants posterior to the mental foramen. J Oral Implantol 2001; 27:127-33.

3. Talesh KT, Solahaye-Kahnamouii S .Application of Crestal Anesthesia for Treatment of Class I Caries in Posterior Mandibular Teeth. J Dent Res 2011; 5:17-22.

4. Oulis CJ, Vadiaka GP, Vasilopoulou A. The effectiveness of mandibular infiltration compared to mandibular block anesthesia in treating primary molars in children. J Pediatr Dent 1996; 18:301-5.

5. Champan PJ. Postoperative pain control for outpatient oral surgery. J Endod 2003; 28:89-91.

6. Snell R. Clinical anatomy by regions, 9th ed.; 2012.p. 610

7. Choi EH, Seo JY, Jung BY, Park W. Diplopia after inferior alveolar nerve block anesthesia: report of 2 cases and literature review. Oral Surg Oral Med Oral Pathol Oral Radiol Endod 2009; 107:21-4.

8. Etoz1 OA, Erl N, Demirbas AE. Issupraperiosteal infiltration anesthesia safe enough to prevent inferior alveolar nerve during posterior mandibular implant surgery. Med Oral Patol Oral Cir Bucal 2011; 16:386-9.

9. Madeira $M C$, Percinoto $C$, das Graças $M$, Silva M. Clinical sig-nificance of supplementary innervation of the lower incisor teeth: a dissection study of the mylohyoid nerve. OralSurg Oral Med Oral Pathol 1998; 46:608-14.

10. Pogrel MA, Smith R, Ahani R. Innervation of the mandibular inci-sors by the mental nerve. J Oral MaxillofacSurg 1997; 55:961-3.

11. Sutton RN. The practical significance of mandibular accessory fo-ramina. Aust Dent $\mathrm{J}$ 1994; 19:167-73. 